that sufficient resources (including suitable accommodation) are made available, that services are made attractive to patients, and that active steps are taken to recruit long term mentally ill people into them.

Community services offering open access (as both services did) commonly attract substantial numbers of clients with less serious symptoms or no symptoms at all. ${ }^{35}$ Provision dedicated to the needs of the long term mentally ill may need to be established to prevent this unintended redirection of resources to clients who would not previously have been recruited into the psychiatric system. Dedicated provision may also encourage the more proactive or assertive approach to recruiting the long term mentally ill into services, which has met with some success. ${ }^{36}$

We thank the trustees of St Thomas's Hospital for funding this study; the patients and their relatives, who volunteered to be interviewed; Dr A Lakhani, Dr T Craig, Dr P Burney, M Morgan, and S Chinn for much useful advice; and the Personal Social Services Research Unit, University of Kent.

1 Groves T. After the asylums: the future of community care. $B M$ 1 $^{1990 ; 300}$ 923-4.

2 Knapp M, Cambridge P, Thomason C, Beecham J, Allen C, Darton R. Care in the community: lessons from the demonstration programme. Canterbury: Personal Social Services Research Unit, University of Kent, 1990.

3 North East Thames Regional Health Authority. Fourth annual conference of the team for the assessment of psychiatric services: summary of proceedings. London: North East Thames Regional Health Authority, 1989.

4 Jones $\mathrm{K}$, Robinson M, Golightley M. Long term psychiatric patients in the community. Br f Psychiatry 1986; 149:537-40.

Milner G. Worcester development project: the closure and replacement of a mental hospital. Health Trends 1991;4:141-5.

6 National Schizophrenia Fellowship. Slipping through the net. Surbiton, Surrey: NSF, 1989.

7 Fry AH, Timms PW. Homelessness and mental illness. Health Trend 1989;21:70-1.

8 Weller M. Psychosis and destitution at Christmas 1985-88. Lancet 1989;ii: 1509-11.

Coid JW. Mentally abnormal prisoners on remand. I. Rejected or accepted by the NHS? BMF 1988:296:1779-82.

10 Davis A, Dinitz S, Pasamanick B. Schizophrenics in the new custodial community. Columbus, Ohio: Ohio University Press, 1974

11 Johnstone EC, Owens DGC, Gold A, Crow TJ, MacMillan JF. Schizophreni patients discharged from hospital-a follow-up study. Br $\mathcal{F}$ Psychiatr 1984; 145:586-90.

12 Tantum D. Alternatives to psychiatric hospitalisation. $\mathrm{Br} \mathcal{F}$ Psychiatr 1985;146:1-4
13 West Lambeth Health Authority. Toward informed action for health: first annual report of the directorate of public health. London: West Lambeth Health

14 Wood S. Home treatment and crisis intervention in Lewisham. In: Brockington I, Hall P, eds. The closure of mental hospitals. London: Gaskell, 1990

15 Rice P, Irving D, Davies G. Information about district health authorities in England from the 1981 census. London: King's Fund, 1984.

16 Spitzer RL, Endicott J, Robins E. Research Diagnostic Criteria instrument No 58. New York: New York State Psychiatric Institute, 1975.

17 Wing JK, Cooper J, Sartorius N. The measurement and classification of psychiatric symptoms. Cambridge: Cambridge University Press, 1974.

18 World Health Organisation. WHO psychiatric disability assessment schedule Geneva: WHO, 1988

19 Ellis RE, Wilson NZ, Foster MF. Statewide treatment outcome assessment in Colorado: the Colorado client assessment record. Community Ment Health f 1984:20:72-89

20 Knapp M, Beecham J. Costing mental health services. Psychol Med (in press)

21 Norusis MJ. Statistical package for the social sciences PC+. Chicago: SPSS, 1986.

22 Dean AD, Dean JA, Burton JH, Dicker RC. Epi-info. Version 5. Atlanta, Georgia: Centers for Disease Control, 1990.

23 Hogg LI, Brooks N. New chronic schizophrenic patients: a comparison of day patients and inpatients. Acta Psychiatr Scand 1990;81:271-6.

24 Bachrach L. The homeless mentally ill and mental health services: an analytical review of the literature. Washington: US Department of Health and Human Services, 1984

25 Cheadle AJ, Freeman HL, Korer J. Chronic schizophrenic patients in the community. Br F Psychiatry 1978;132:221-7.

$26 \mathrm{McC}$ readie RG. The Nithsdale schizophrenia survey. I. Psychiatric and social handicaps. Br f Psychiatry 1982;140:582-6.

27 Watt DC, Katz K, Shepherd M. The natural history of sc̈izophrenia: a five year follow up. Psychol Med 1983;13:663-70.

28 Cramer P, Weegmann M, O'Neil P. Schizophrenia and the perception of emotions: how accurately do schizophrenics judge the emotional state of others? Br f Psychiatry 1989;155:225-8.

29 Kuipers L, Bebbington P. Expressed emotion research in schizophrenia: theoretical and clinical implications. Psychol Med 1988;18:893-910.

30 The National Health Service and Community Care Act 1990. London: HMSO, 1990.

31 Khoosal D, Jones P. Worcester development project: where do patients go when hospitals close? Health Trends 1991;22:137-41.

32 Beecham J, Knapp M, Fenyo A. Costs, needs and outcomes: community care for people with long term mental health problems. Schizoph Bull (in press) 33 Thornicroft $G$, Bebbington P. Deinstitutionalisation - from hospital closure service development. Br f Psychiatry 1989;155:739-53.

34 Department of Health. The care programme approach for people with a mental illness referred to the specialist psychiatric services. London: Department of Health, 1990. (HC(90)23/LASS(90)11.

35 Sayce L, Craig TJK, Boardman AP. The development of community mental health centres in the UK. Soc Psychiatry and Psychiatr Epidemiol 1991;26: 14-20.

36 Olfson $M$. Assertive community treatment: evaluation of the experimental evidence. Hosp Community Psychiatry 1990;41:634-41.

\title{
Intravenous acetylcysteine in paracetamol induced fulminant hepatic failure: a prospective controlled trial
}

\author{
R Keays, P M Harrison, J A Wendon, A Forbes, C Gove, G J M Alexander, Roger Williams
}

Institute of Liver Studies, King's College School of Medicine and Dentistry, London SE5 8RX

R Keays, MRCP, clinical research fellow

P M Harrison, MRCP, clinical research fellow

J A Wendon, MRCP, clinical research fellow

A Forbes, MD, clinical research fellow

C Gove, PHD, senior research fellow

G J M Alexander, MRCP, senior lecturer Roger Williams, FRCP, director

Correspondence and requests for reprints to: Dr Williams.
Abstract

Objective-To see whether intravenous acetylcysteine would improve outcome in patients with fulminant hepatic failure after paracetamol overdose.

Design-A prospective randomised controlled study.

Setting - The Institute of Liver Studies, King's College Hospital, London.

Patients -50 consecutive patients $(21$ male) aged 16-60 with fulminant hepatic failure after paracetamol overdose who had not previously received acetylcysteine.

Interventions-Conventional intensive liver care plus either acetylcysteine ( 25 patients) in the same dose regimen as used early after a paracetamol overdose, except that the infusion was continued until recovery from encephalopathy or death, or an equivalent volume of $5 \%$ dextrose ( 25 patients).

Main outcome measures-Survival; incidence of cerebral oedema, renal failure, and hypotension requiring inotropic support; liver function as assessed by prolongation of the prothrombin time; and degree of encephalopathy.
Results-The rate of survival was significantly higher in the acetylcysteine treated group than in the controls $(48 \%$ (12/25 patients) $v 20 \%(5 / 25)$; $\mathrm{p}=0.037,95 \%$ confidence interval for difference in proportions surviving $3 \%$ to $53 \%$ ). Acetylcysteine treated patients had a lower incidence of cerebral oedema $(40 \%(10 / 25) v 68 \%(17 / 25) ; \mathrm{p}=0.047,95 \%$ confidence interval for difference in incidence $2 \%$ to $54 \%$, and fewer developed hypotension requiring inotropic support $(48 \%(12 / 25)$ v $80 \%(20 / 25)$; $p=0.018,95 \%$ confidence interval $7 \%$ to $57 \%$ ). Rates of deterioration and recovery of liver function, however, were similar in the two groups. No adverse reactions to acetylcysteine were seen.

Conclusions-Acetylcysteine is safe and effective in fulminant hepatic failure after paracetamol overdose.

\section{Introduction}

Acetylcysteine, by repleting glutathione stores,' is highly effective in preventing massive hepatic necrosis if given within 10 hours of a paracetamol overdose, and it reduces the severity of liver damage if given up to 15 
hours after drug ingestion..$^{23}$ Until recently it was thought that initiating intravenous acetylcysteine more than 15 hours after overdose was of no benefit, Prescott et al having shown that it does not prevent severe liver damage when given at that stage. ${ }^{2}$ The reluctance to use acetylcysteine late after overdose was strengthened by work in animals suggesting that late use might even be harmful. ${ }^{4}$ However, acetylcysteine given late after overdose has now been shown not to be hepatotoxic. In a retrospective study of patients with fulminant hepatic failure after paracetamol overdose we found a better outcome when acetylcysteine was given 10 to 36 hours after overdose, despite no apparent enhancement of liver function as assessed by prolongation of the prothrombin time. ${ }^{6}$

Evidence is also accumulating that acetylcysteine is of benefit in other critical illnesses. A study in a porcine model of endotoxin induced multiorgan failure ${ }^{7}$ and an anecdotal report of multiorgan failure in a patient with pancreatitis ${ }^{8}$ suggested that acetylcysteine given after the onset of critical illness may ameliorate the multiorgan failure. We report the results of a prospective randomised controlled trial of intravenous acetylcysteine in patients with established fulminant hepatic failure after paracetamol overdose.

\section{Patients and methods}

Patients with fulminant hepatic failure ${ }^{9}$ after paracetamol overdose who had not already received acetylcysteine were eligible for the trial. Patients were randomised on admission to the liver failure unit by opening one of 50 identical sealed envelopes containing an allocation to receive either acetylcysteine in addition to conventional intensive liver care ${ }^{10-12}$ or the same level of intensive care alone. Twenty five patients were randomised to receive acetylcysteine, which was given by intravenous infusion using the regimen recommended after paracetamol overdose-namely, $150 \mathrm{mg} / \mathrm{kg}$ body weight in $200 \mathrm{ml} 5 \%$ dextrose over 15 minutes, followed by $50 \mathrm{mg} / \mathrm{kg}$ in $500 \mathrm{ml} 5 \%$ dextrose over four hours, then $100 \mathrm{mg} / \mathrm{kg}$ in 1 litre over 16 hours. The final infusion rate was continued until recovery from encephalopathy or death. Control patients received an equivalent amount of $5 \%$ dextrose without acetylcysteine. Treatment with acetylcysteine could not be given blind because the solution has an easily identified pungent aroma.

Intensive liver care for all patients included routine insertion of a pulmonary artery flotation catheter and radial arterial line. Intravascular filling pressures were maintained with infusion of appropriate colloid solutions (blood or $4.5 \%$ human albumin solution). If patients had oliguria despite an adequate pulmonary capillarv wedge pressure of greater than $12 \mathrm{~mm} \mathrm{Hg}$ a dopamme infusion was begun at $2 \mu \mathrm{g} / \mathrm{kg} / \mathrm{min}$. Renal replacement therapy with either intermittent haemodialysis or continuous arteriovenous haemofiltration

TABLE I-Characteristics of study groups. Except where stated otherwise values are medians (ranges)

\begin{tabular}{|c|c|c|}
\hline & Acetylcysteine & Control \\
\hline No of patients & 25 & 25 \\
\hline Age (years) & $33(17-60)$ & $34(16-58)$ \\
\hline $\operatorname{Sex}(M / F)$ & $12 / 13$ & $9 / 16$ \\
\hline Hours from overdose to presentation to referring hospital & $28(16-36)$ & $32(16-48)$ \\
\hline Hours from overdose to admission to liver failure unit & $53(36-80)$ & $56(33-96)$ \\
\hline \multicolumn{3}{|l|}{ Values at entry to trial: } \\
\hline Serum creatinine $(\mu \mathrm{mol} / \mathrm{l})$ & $246(86$ to 620$)$ & $247(71-574)$ \\
\hline Arterial pH & $7 \cdot 39(6 \cdot 89$ to $7 \cdot 48)$ & $7 \cdot 39(7 \cdot 08-7 \cdot 53)$ \\
\hline Prothrombin time (s; control time $15 \mathrm{~s})$ & $115(29$ to 180$)$ & $140(29$ to 180$)$ \\
\hline \multicolumn{3}{|l|}{ No of patients fulfilling criteria for poor prognosis: } \\
\hline Admission $\mathrm{pH}<7 \cdot 30$ & 8 & 5 \\
\hline $\begin{array}{l}\text { Prothrombin time }>100 \mathrm{~s}+\text { serum creatinine }>300 \mu \mathrm{mol} / 1+\text { grade } 3 \\
\text { or } 4 \text { coma }\end{array}$ & & 11 \\
\hline $\begin{array}{l}\text { or } 4 \text { coma } \\
\text { Rise in prothrombin time on day } 4 \text { compared with day } 3 \text { after }\end{array}$ & 9 & 11 \\
\hline $\begin{array}{l}\text { overdose } \\
\text { No of patients fulfilling at least one criterion for poor prognosis }\end{array}$ & 5 & 5 \\
\hline No of patients fulfilling at least one criterion for poor prognosis & 17 & 18 \\
\hline
\end{tabular}

was instituted if the patient had anuria or oliguria with a serum creatinine concentration greater than $400 \mu \mathrm{mol} / \mathrm{l}$. Hypotension, defined as a mean arterial pressure of less than $60 \mathrm{~mm} \mathrm{Hg}$ despite adequate intravascular filling pressures, was treated with either adrenaline or noradrenaline as vasopressor support. Patients who progressed to grade 4 encephalopathy were electively ventilated (Siemens servo 900C, volume control) and given a continuous infusion of muscle relaxant (atracurium $50 \mathrm{mg} / \mathrm{h}$ ). The development of raised intracranial pressure due to cerebral oedema was diagnosed from the typical clinical signs (systemic hypertension and dilated pupils) and treated with mannitol, hyperventilation, and thiopentone according to the response.

Blood samples for haematological and biochemical profiles were taken on admission and each morning thereafter. The incidence of cerebral oedema, hypotension, and renal failure together with the daily haematological and biochemical profiles were recorded for each patient for later analysis. Particular attention was paid to the known indicators of poor prognosis: arterial $\mathrm{pH}<7 \cdot 3$, prothrombin time $>100$ s accompanied by a serum creatinine concentration $>300 \mu \mathrm{mol} / 1$ in a patient with grade 3 or $4 \mathrm{coma},{ }^{13}$ and a rise in the prothrombin time on day 4 compared with day 3 after overdose. ${ }^{14}$ On the basis of these predictors two women who had been randomised to the acetylcysteine group underwent orthotopic liver transplantation; for the statistical analysis we assumed that they would have died.

Statistical analysis-In order to detect a $40 \%$ difference in survival between the acetylcysteine treated and control groups we had calculated that we would need to recruit 25 patients in each group to give a $90 \%$ power of achieving 5\% significance. The retrospective study of late treatment with acetylcysteine in patients after paracetamol overdose who subsequently developed fulminant hepatic failure had suggested that such a difference in survival might be achieved. ${ }^{6}$ Analysis of the difference in outcome between the two groups was performed by $\chi^{2}$ test. This test was also used to compare groups for the incidence of hypotension, cerebral oedema, and renal failure. Results were considered significant if $\mathrm{p}<0.05$ and were expressed with the $95 \%$ confidence intervals for the difference in incidence of these variables between the groups. The Mann-Whitney U test was used for the comparison of prothrombin time and grade of encephalopathy. The time to death in the two groups was compared by log rank test. Survivors were censored at 21 days, although there were no further deaths after 16 days in the trial.

Ethics - The study was approved by the King's College Hospital and Medical School ethics committee.

\section{Results}

The characteristics of the acetylcysteine and control groups at entry to the trial are shown in table I. They were well matched for age and sex. There were no significant differences between the groups in the time from overdose to either presentation at the referring hospital or admission to the liver failure unit at this hospital. Admission values of serum creatinine concentration, arterial $\mathrm{pH}$, and prothrombin time were similar. At entry a similar number of patients in each group fulfilled the criteria for poor outcome.

Forty eight per cent of patients (12/25) in the acetylcysteine treated group survived compared with $20 \%(5 / 25)$ of the controls $(\mathrm{p}=0.037 ; 95 \%$ confidence interval for difference in survival between groups 3\% to $53 \%$ ). Five of the 17 patients in the acetylcysteine treated group who fulfilled at least one criterion for poor prognosis survived compared with only one of the 18 patients in the control group; this difference was not 


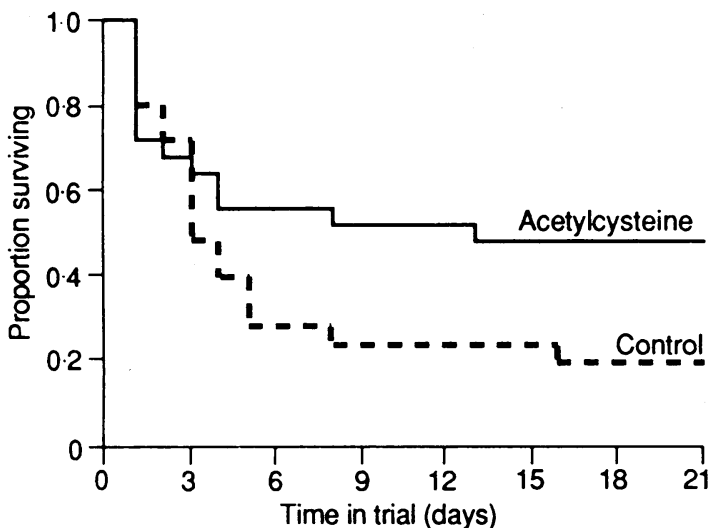

Proportions of patients surviving in acetylcysteine treated and control groups on each day after start of trial

significant $\left(\chi^{2}=3 \cdot 5, \mathrm{df}=1 ; \mathrm{p}=0 \cdot 06\right)$. The time to death in days was similar in the treated and control groups $\left(\chi^{2}=2 \cdot 4\right.$ from Mantel-Haenszel procedure, $\left.\mathrm{df}=1\right)$. Survival curves are shown in the figure.

Fewer patients treated with acetylcysteine developed clinical signs of cerebral oedema compared with controls $(40 \%(10 / 25) v 68 \%(17 / 25), \mathrm{p}=0.047$, $95 \%$ confidence interval for difference in incidence $2 \%$ to $54 \%$ ) despite a comparable severity of liver failure as assessed by prolongation of the prothrombin time and grade of encephalopathy (table II). The development of cerebral oedema was associated with a poor outcome in both groups, no patients in the control group and only two in the acetylcysteine treated group surviving. Adrenaline or noradrenaline was given to maintain mean arterial pressure in fewer patients receiving acetylcysteine than controls $(48 \%(12 / 25) \quad v 80 \%$ (20/25); $p=0 \cdot 018,95 \%$ confidence interval for difference in incidence $7 \%$ to $57 \%$ ). The occurrence of hypotension requiring inotropic support was also associated with a poor outcome, no patients in the control group and only two in the acetylcysteine treated group surviving. The proportion of patients requiring renal support was lower in the acetylcysteine treated group than the control group $(40 \%(10 / 25) v$ $60 \%(15 / 25))$ but the difference was not significant (95\% confidence interval for difference in incidence $7 \%$ higher to $47 \%$ lower).

Acetylcysteine was well tolerated by all patients, none having evidence of a hypersensitivity reaction.

\section{Discussion}

These findings show that intravenous acetylcysteine significantly improves survival in patients with fulminant hepatic failure after paracetamol overdose. That the median prothrombin time was similar on each day of the trial in the acetylcysteine treated and control groups is consistent with findings in the previous uncontrolled study from this unit, in which acetylcysteine improved survival without having a measurable effect on liver function. ${ }^{6}$ However, although prolongation of the prothrombin time is a good indicator of the severity of liver damage, it is only one measure of hepatic function.

TABLE II - Prothrombin times (control time $15 \mathrm{~s}$ ) and grades of encephalopathy in acetylcysteine treated and control groups at entry and during first four days of trial. Values are medians (ranges)

\begin{tabular}{|c|c|c|c|c|c|}
\hline & At entry & Day 1 & Day 2 & Day 3 & Day 4 \\
\hline & \multicolumn{5}{|c|}{ Prothrombin time (s) } \\
\hline Acetylcysteine & $115(29-180)$ & $96(25-180)$ & $60(20-180)$ & $41(16-180)$ & $28(16-180)$ \\
\hline \multirow[t]{2}{*}{ Control } & $140(29-180)$ & $114(24-180)$ & $67(18-180)$ & $45(17-180)$ & $46(16-146)$ \\
\hline & \multicolumn{5}{|c|}{ Encephalopathy grade } \\
\hline Acetylcysteine & $2(1-4)$ & $4(1-4)$ & $\begin{array}{l}4(0-4) \\
4\end{array}$ & $4(0-4)$ & $4(0-4)$ \\
\hline Control & $3(1-4)$ & $4(0-4)$ & $4(0-4)$ & $4(0-4)$ & $4(0-4)$ \\
\hline
\end{tabular}

There were no significant differences in prothrombin time or encephalopathy grade between the groups on any day.
The lower incidence of cerebral and cardiovascular dysfunction may account for the enhanced survival in acetylcysteine treated patients as recovery from any cause of multiorgan failure, including fulminant hepatic failure, ${ }^{15}$ is inversely related to the number of failing organs and the duration of their dysfunction. ${ }^{16}$ An important cause of organ failure is tissue hypoxia, which may arise in fulminant hepatic failure because tissue oxygen consumption becomes dependent on oxygen delivery over a greater range than normal. ${ }^{17}$ Although this may be increased, it is inadequate to supply sufficient oxygen for tissue requirements in the presence of the reduced ability to extract oxygen. Acetylcysteine enhances tissue oxygen consumption in fulminant hepatic failure not only by improving oxygen delivery to tissues but also by increasing peripheral oxygen extraction..$^{18}$ The reversal of tissue hypoxia after infusion of acetylcysteine may account for the lower incidence of multiorgan failure. The mechanism by which acetylcysteine improves tissue oxygen extraction in fulminant hepatic failure is poorly understood, but we have suggested that it increases microcirculatory blood flow by correcting a relative deficiency in the activity of endothelium derived relaxing factor. ${ }^{18}$

Oxidant stress, mediated by either oxygen free radicals or the direct oxidant action of reactive metabolites of paracetamol, can cause endothelial cell damage $^{19}$ and may contribute to some of the complications, such as cerebral oedema. Paracetamol overdose promotes the conversion of xanthine dehydrogenase to xanthine oxidase, producing activated oxygen free radicals which can oxidise important protein thiol groups. ${ }^{20}$ Oxidation of essential thiol groups in $\beta$ adrenoceptors has been shown to reduce the inotropic effect of $\beta$ adrenoceptor agonists in an animal model. ${ }^{21}$ The depression of myocardial contractility induced by oxygen free radicals can be prevented by acetylcysteine, ${ }^{22}$ which is an avid scavenger of oxygen free radicals. ${ }^{23}$ The prevention or reversal of oxidation of thiol groups in $\beta$ adrenoceptors could explain the reduced inotropic requirements in acetylcysteine treated patients.

It had been thought that giving acetylcysteine late after paracetamol overdose would be associated with a high incidence of hypersensitivity reactions. However, no adverse reactions were encountered. Many of the reactions reported with acetylcysteine in the past were associated with high doses of the drug. The elimination of acetylcysteine is not impaired in severe liver damage ${ }^{24}$ and it is unlikely that toxic concentrations would be achieved with the dosage regimen used in this study.

We are grateful to Dr John Spooner, of Sterling Research Laboratories, for generous support of studies of paracetamol hepatotoxicity.

1 Miners JO, Drew R, Birkett DJ. Mechanism of action of paracetamo protective agents in mice in vivo. Biochem Pharmacol 1984;33:2995-3000.

2 Prescott LF, Illingworth RN, Critchley JAJH, Stewart MJ, Adam RD, Proudfoot AT. Intravenous $\mathrm{N}$-acetylcysteine: the treatment of choice for Proudfoot AT. Intravenous N-acetylcysteine: the

3 Rumack BH, Peterson RC, Koch GC, Amara IA. Acetaminophen overdose 662 cases with evaluation of oral acetylcysteine treatment. Arch Intern Med 1981:141:380-5.

4 Banda PW, Quart BD. The use of $\mathrm{N}$-acetylcysteine long after an acetaminophen overdose in mice. Toxicol Lett 1987;36:89-94.

5 Parker D, White JP, Paton D, Routledge PA. Safety of late acetylcysteine treatment in paracetamol poisoning. Hum Exp Toxicol 1990;9:25-7.

6 Harrison P, Keays R, Bray G, Alexander G, Williams R. Improved outcome in paracetamol-induced fulminant hepatic failure following late administration of $\mathrm{N}$-acetylcysteine. Lancet 1990;335:1572-3.

7 Modig J, Sandin R. Haematological, physiological and survival data in porcine model of adult respiratory distress syndrome induced by endotoxaemia. Effects of treatment with $\mathrm{N}$-acetylcysteine. Acta Chir Scand 1988;154:169-77.

8 Braganza JM, Holmes AM, Morton AR, Stalley L, Ku R, Kisher R. Acetylcysteine to treat complications of pancreatitis [letter]. Lancet 1986; ; 914-5.

9 Trey C, Davidson CS. The management of fulminant hepatic failure. In: 
Popper H. Shaffner F, eds. Progress in liver disease. Vol 3. New York: Grune and Stratton, 1970:282-98.

10 Williams R. Management of acute liver failure. Postgrad Med J 1988;64: 769-71.

11 O'Grady JG, Williams R. Management of acute liver failure. Schweiz Med Wochensichr 1986;116:541-4.

12 O'Grady JG, Williams R. Acute liver failure. Baillieres Clin Gastroenterol 1989:3:75-89.

13 O'Grady J, Alexander (jJ.M, Havllar KM. Williams R. Early indicators of prognosis in fulminant hepatic failure. Gastroenterologv 1989;97:439-45.

14 Harrison PM. O'Grady JG, Keays R, Alexander GJM, Williams R. Serial prothrombin time as prognostic indicator in paracetamol-induced fulminant hepatic failure. BMF 1990;301:964-6.

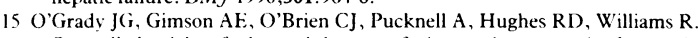
Controlled trials of charcoal hemoperfusion and prognostic factors in fulminant hepatic failure. Gastroenterology 1988;94:1186-92

16 Knaus WA, Draper EA, Wagner EP, Zimmerman JE. Prognosis in acute organ-system failure. Ann Surg 1985;202:685-93.

17 Bihari DJ, Gimson AE, Williams R. Cardiovascular, pulmonary and renal complications of fulminant hepatic failure. Semin Liver Dis 1986;6:119-28.

18 Harrison PM, Wendon JA, Gimson AES, Alexander GJM, Williams R.
Improvement by acetvlcysteine of hemodynamics and oxygen transport in fulminant hepatic failure. $N$ Engl F Med 1991;324:1852-7.

19 De Leve LD, Kaplowitz N. Hepatic endothelial cells as a target for acetaminophen (APAP) toxicity [abstract]. Hepatology 1990;12:A1009.

20 Tirmenstein MA, Nelson SD. Acetaminophen-induced oxidation of protein thiols. Contribution of impaired thiol-metabolizing enzymes and the hiols. Contribution of impaired thiol-metabolizing enzymes

21 Haenen G. Reduction of $\beta$-adrenoceptor function by oxidative stress in the heart. In: Thiols in oxidative stress, some implications for catecholamine toxicity. Amsterdam: Free University Press, 1989:151-66. (Dissertation.)

22 Artman M, Olson RD, Boucek RJ, Boerth RC. Depression of contractility in isolated rabbit myocardium following exposure to iron: role of free radicals. Toxicol Appl Pharmacol 1984;72:324-32.

23 Aruoma O, Halliwell B, Hoey B, Butler J. The antioxidant action of $\mathrm{N}$-acetylcysteine: its reaction with hydrogen peroxide, hydroxyl radical, superoxide, and hypochlorous acid. Free Radic Biol Med 1989;6:593-7.

24 Prescott L, Donovan J, Jarvie D, Proudfoot A. The disposition and kinetics of intravenous $\mathrm{N}$-acetylcysteine in patients with paracetamol overdosage. Eur f Clin Pharmacol 1989;37:501-6.

(Accepted 6 August 1991)

\title{
Use of psychiatric services by patients in a general hospital
}

\author{
Richard Mayou, Valerie Seagroatt, Michael Goldacre
}

\begin{abstract}
Objective-To identify physical disorders associated with increased rate of use of psychiatric services.

Design-Retrospective analysis of routine abstracts of general hospital inpatient records linked with those of psychiatric care, for inpatients with physical disorders with possible psychiatric associations and for controls.

Setting-Oxfordshire health district.

Subjects - Inpatients aged 15-64 years discharged from general hospitals during 1975-85 with a diagnosis among 14 selected diagnostic groups (including potentially life threatening conditions, chronic disabling diseases, and non-specific symptomatic conditions) and control inpatients with acute conditions.
\end{abstract}

Main outcome measures-Observed and expected numbers of patients receiving psychiatric care.

Results-Observed use of psychiatric services before and after index admission was close to that expected for controls. For most other diagnoses the observed use was significantly increased in the year preceding and that subsequent to the admission. For four diagnostic groups it was significantly greater in the year after admission than in that before (acute myocardial infarction (ratio before to after $2 \cdot 17,95 \%$ confidence interval 1.5 to 3.3$)$, cancer $(2.05,1.7$ to $2 \cdot 5)$, diabetes mellitus $(1.89,1.4$ to $2 \cdot 9)$, and chest pain $(1.78,1.3$ to 2.4$)$ ). During four years after the admission the use of psychiatric services was signifcantly higher than in the general population for nonspecific symptomatic conditions (observed/expected: abdominal pain $1 \cdot 7$, chest pain $2 \cdot 0$, and headache $4 \cdot 2$ ), cirrhosis of the liver (10.4), and fractures in road accidents and other fractures $(1 \cdot 3,1 \cdot 6)$.

Conclusions-More patients with certain physical conditions used psychiatric services. Alternative methods of service delivery may be needed, especially for disabling chronic physical illness, alcohol related disorders, and non-specific symptomatic conditions.

\section{Introduction}

Associations between psychiatric disorder and physical symptoms and conditions are evident in the general population, ${ }^{1-3}$ in people attending primary care services, ${ }^{4}$ and in patients in general hospitals. ${ }^{5.9}$ Explanations for such associations include psychiatric disorder as a reaction to physical illness, psychiatric disorder presenting with somatic symptoms, physical complications of psychiatric disorders, and aetiological or other risk factors common to both psychiatric and physical disorders. Other important factors which may result in associations between disorders include illness and consultation behaviour ${ }^{4}$ and referral and admission practice $^{7.4}$ and the possibility that people with two disorders may be more likely to receive specialist care than those with either disorder alone. ${ }^{10}$

Psychiatric illness among patients in general hospitals is important, both because it can be a persistent disability and because it is associated with poor compliance with medical treatment and extra demands on medical resources. ${ }^{511-13}$ Unfortunately, such illness is not always recognised and, if recognised, treated. Few patients are referred to specialist psychiatric consultation services within general hospitals. ${ }^{14} 15$

We considered that it would be useful to quantify the use of psychiatric services by patients in general hospitals and to identify particular types of physical problem associated with increased rate of use of psychiatric services. Such information could have implications for the delivery of psychiatric and other psychological services and may also provide evidence of aetiological associations between physical and psychiatric disorders.

We used abstracts of general hospital inpatient records linked with abstracts of psychiatric care to study the use of psychiatric services by patients in general hospitals with a diagnosis on discharge among 14 groups of chosen diagnoses. The use of psychiatric services was compared, firstly, with that by the general population in the same health district and, secondly, with a group of patients in general hospitals selected as controls. The diagnoses were chosen to illustrate physical conditions which may be life threatening and distressing (for example, myocardial infarction and cancer); those which might in some patients be an expression of psychiatric disorder (for example, chest pain, abdominal pain, and headache); those in which physical disorder may be the consequence of psychiatric disorder (for example, cirrhosis after chronic alcohol problems); and those in which associations between physical and psychiatric conditions may exist but whose nature may be more complex.

\section{Patients and methods}

The Oxford record linkage study consists of brief abstracts of inpatient general and psychiatric hospitals, 